\title{
3 To Describe Genres: Problems and Strategies
}

\author{
Maria Antónia Coutinho \\ Florencia Miranda
}

\section{INTRODUCTION}

The relation between genre as an abstract category and text as an empirical object that is always an example of a certain genre raises epistemological and methodological questions. There seems to be a consensus in the literature on genre theory, the description of genres raises difficulties - taking into consideration, on the one hand, the multiplicity of facts and criteria that may intervene in this descriptive work, and on the other hand, the changing nature that characterizes genres (because they are theoretically in an infinite number). Simultaneously, it is accepted that any text is related to a genre, which may be more formally or more freely reproduced. Therefore, it is needed to think, methodologically, about the viability of the description of genres - mainly if we consider that, we can only have access to those through empirical texts that are an example of genre. How can we stablely describe and analyze genresthat are only observed through texts that are actually produced? Which are the epistemological forms that can sustain effective work on genres? Which are the methodological specifications?

In this paper we are going to show some strategies for dealing with this problematic. On the one hand, it is important to be aware of the duality necessarily entangled in the production and interpretation of texts: on one side, the common plan that guarantees "a family pattern" (it must be underlined, without the inclusion of rules or universal ambitions) and on the other side the plan of singularity that makes any text unique. Within this scope, we must define the means of organized analysis recognizing the duality of genre and text - and supporting the specification of the genres (that, as we have underlined, are unontological entities). Besides, methodological procedures suitable to work with the genres must be considered - mainly, concerning the need to create differentiated conditions for observing the texts, without recourse to manipulations, more or less controlled.

On the following pages, we will start with a brief scenery of some expressive landmarks, concerning the possible analysis of the genres and the textslighting some pertinent gaps in this context. Later on, some positive suggestions will be presented - on the one hand related to the separation of analysis plans, 
interfering with the notion of parameters of genre and mechanisms of textual realization; on the other hand, presenting genre fictionalization as a methodological strategy which, assuring the preservation of natural, text circulation conditions, offers up for analysis genres manipulated without the intervention of researchers. For analysis of genre fictionalization, we will further introduce the notion of genre marker.

\section{GENRES AND TEXTS: PROBLEMS WITH DESCRIPTION}

One of the arguments usually mentioned to justify the impossibility of descriptive work is the diversity and the mutability which characterize genres. Theoreticians and analysts seem to concur on these characteristics; however, these characteristics do not seem to prevent the genres from working. In other words, despite diversity and mutability, speakers and writers, when they speak or write (and when they listen or read) do not have difficulty in identifying and using genres they have experience with and which are part of their contemporary social world.

Another strong argument presented against description concerns the multiplicity of factors in interaction which mobilises each genre. That is why, it is obvious that the several typological attempts (situational, enunciative and functional), necessarily partial, are inevitably vowed to failure. Even if the typological attempt is rejected - taking into consideration that it contradicts the virtually unlimited expansion to which genres are subjected-the conviction remains strongly, that the quantity of potential criteria makes the description unfeasible.

Without questioning the validity of these arguments, nonetheless, methodologically, the impossibility of any exhaustive classification of genres does not necessarily correspond to a radical impossibility of description. The general methodological thesis important to resume work is the need to think out suitable methodological strategies and instruments of analysis to objects known as unstable.

Despite the problems of mutability and diversity, the literature has developed ways of describing literature. In agreement with Bakhtin, we may consider that the description of any genre has at least three components: the thematic subject, the composition and the style (Bakhtin, 1984, p. 265). It is not sure if these points are enough for complete description. Nonetheless, Bakhtin's proposal still seems to be a good suggestion for work in the sciences of languagewhich are slowly moving from a logical-grammatical approach to a rhetoricalhermeneutical approach (Rastier, 2001) ${ }^{1}$. Concerning the thematic subject, very little was advanced after Voloshinov's struggle (assigned to Bakhtin) to clarify the notions of theme and meaning, putting in perspective the energetic way the 
second is related to the first: "Meaning means nothing in and of itself, it is but potential, a possibility of signifying within a concrete theme" (Bakhtin, 1977, p. 145). Though as a simple suggestion, it is worthwhile to underline the way this concept shows perspectives for analysis that later studies on texts and genres have not completely developed: the relationship between theme and genre; the relationship between the theme and other facts involved in generic format; and the relationship between meaning (or language) and the genres.

In the following paragraphs, we are going to distinguish the contributions of Adam and Bronckart. To Adam, we owe a lengthy reflection on the regularities of elements of text composition, particularly text types and/or prototype sequences, with which Adam is most closely associated. We will also consider his work on other elements to be considered in textual composition: simple periods (which, unlike the sequences, are not typified) and text plans, which may be fixed (depending on the genre concerned) or occasional (Adam, 2002a, pp. 174175).

Jean-Paul Bronckart $(1997,2006)$, within the theoretical-epistemological approach called socio-discursive interactionism (hereafter ISD), on the other hand approaches description of texts, not genres. Nonetheless, Bronckart does consider the general text substructure, which he proposes as having the following elements:

- the text plan (which organizes the theme);

- types of discourse, to be understood as modes of enunciation (interactive discourse and theoretical discourse, for the explanatory mode; interactive report and narration, for the narrative mode) ${ }^{2}$;

- possibilities of articulation between types of discourse (embedding and fusion, among other possibilities);

- sequences (narrative, descriptive, injunctive, explicative, argumentative, dialogical);

- other planning means (the schematization, as the minimal form of the explanatory mode, where the object is presented in a purely explanatory manner, as in definitions, enumerations and in enunciating rules; and the script as the minimal form of the narrative mode, where the linear organization reproduces the chronological order of events, with no process of tension building).

Although we cannot develop here the problematic of style-that alone deserves a profound and up-to-date reflection-it is important to maintain the manner the theme has been put in perspective, namely by Adam (1999). As shown in Figure 1 (Adam, 1999, p. 93), the author distinguishes three different 
zones within the variation possibilities: a normative zone, defined by higher frequency constants; a zone of relative normativization, corresponding to grammar and genres (with more rigid rules for grammar, more flexible rules for genres); and the zone of system variation, where style and text are to be found.

\section{Microlinguistics}

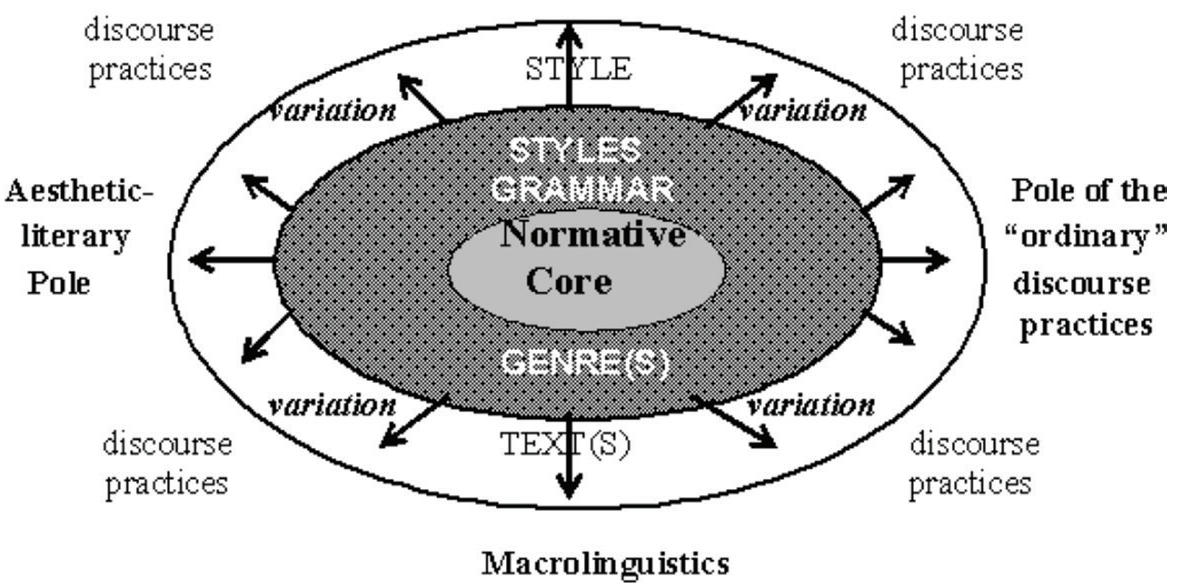

FIGURE 1: STYLE (ADAM, 1999, P. 93)

From the author's point of view, style (in the singular) corresponds to individual variation, while styles (in the plural) should be related to cases of "phraseology of a social group (being it juridical, medical, sportive, etc.) ...” Besides being aware that styles correspond for true, only to those phraseologies, it is important to underline how the genre is an agent of stability and even of standardness, while texts are variation cases, related to genre.

After briefly considering some questions related to the three components mentioned by Bakhtin, we should return to the mentioned topic: what the authors say about the possibility of genre description.

Dominique Maingueneau (1996, p. 44) started to consider the following facts to define a genre ("contraintes définitoires"): the nature of the enunciators and the co-enunciators, the circumstances of space and time associated with enunciation, the support, the theme and the organizing method. In further works, the author has introduced insignificant changes, retaining the following components of genre: finality, place, temporality, nature of the interlocutors, material support/presentation and text organization/plan (Maingueneau, 1998, pp. 51-54; 2002, pp. 55-62). Clearing referring to the contribution of Maingueneau just mentioned, Jean-Michel Adam proposes an extension of the components, taking into consideration eight components: semantics, enunciative, 
pragmatic, stylistic and phraseological, compositional, material, peri-textual and meta-textual (Adam, 2001, pp. 40-41).

Our interest here is not in the number or the nature of the considered components, but in Adam's complete overlap of generic and textual plans, as he asserts that the components of genre correspond to the individual text organization ${ }^{3}$ (2001, p. 28). The justification looks more than evident: admitting, as we have been doing, that the genre does not have ontological reality, the components of genre would be also, necessarily, textual components. Nonetheless the relation that unites the genre to the text effectively produced must be more clearly articulated. Jean-Michel Adam asserts genres regulate the textual practice through two apparently contradictory principles: a principle of identity, oriented for the repetition and the reproduction, and a principle of difference, oriented for the innovation and the variation (Adam, 2002, p. 38). Within this viewpoint, the deficiency of the previous hypothesis has to be recognized - that is, that the same components are not sufficient to analyze simultaneously the genres and the texts. How to give evidence, then, to the innovations that carry out (or are carried out in) concrete texts? How to know if they are still examples of the same initial genre?

Within the socio-discursive interactionism framework, Jean-Paul Bronckart describes the textual architecture through an organization in layers (similar to a puff paste): in the first place, the general substructure, that includes the text plan, types of discourse, sequences and other forms of planning (script and schematization); secondly, mechanisms of textualization (mechanisms of connection, on one side, of verbal and nominal cohesion, on the other); finally, enunciation mechanisms (enunciative responsibilities and modalities).

Jean-Paul Bronckart has underlined systematically that between an empirical text and the genre that it depends on is established a double relation of adoption and of adaptation, as the situation is realized by the producer. However, separating textual architecture from the notion of genre obscures where and how the adoption and the adaptation are done.

In synthesis, we will be able to say that any one of the indicated solutions (to describe the genres or to describe the texts) leaves unresolved the central questions in this problematic - the inter-relation between these categories. Therefore, a repertoire of components of genre does not assure the effective description of any text depending on that same genre; and inversely, a model of architecture of the texts leaves us without any capacity of relation with the formats that those depend on (a more or less strict or more or less creative form).

In the following section, we will describe an assembly of notions/instruments of analysis that will help us bring together the concepts of genre and text architecture. 


\section{PARAMETERS OF GENRE, MECHANISMS OF TEXTUAL REALIZATION AND GENRE MARKERS}

The starting point for the elaboration of the instruments of analysis ${ }^{4}$ that we are going to describe is related to a conviction already referred to above: that the impossibility of any exhaustive classification of genres does not correspond necessarily and inevitably to a radical impossibility of description. This viewpoint situates itself in the same positioning of several authors, already referred to above, who all take into consideration the need to distinguish stability and variation, but without providing a means to make the distinction. Despite, as we already said, that it does not put in perspective the way each text adopts and/ or adapts the genre it depends-Bronckart refers to the "objective differences" in the interior of the architext (Bronckart, 2006, p. 146)—this may suggest the possibility of identifying contrasting aspects of the genres. Adam (1999) attributes to the genres a normative function-more flexible than the normative function of the language as Bakhtin had already mentioned (Bakhtin, 1984, p. 285). Subsequently, Adam formulated again and/or explained this same viewpoint, referring to two guiding principles: a principle of identity (centripetal), oriented for the repetition and the reproduction, performing a normative role; and a principle of difference (centrifugal), oriented for the innovation and the variation (Adam, 2001, p. 38).

So admitting the need to notice the movements of stability and of variation associated with the functioning of the genres, we add a last argument: if we exclude the possibility of description of the genres, we wind up with a model of organization of the texts that cannot describe the relations with the formats that they depend on (a more or less strict, more or less creative form).

Starting from this hypothesis, we propose that the same model of analysis will be able to, and must be applied to both individual empirical texts and to abstract genres. The instrument that we are presenting has been conceived using the frame of the socio-discursive interactionism. To this we have added some ideas of other linguists and discourse analysts, especially to analyze less explicit or less evident aspects 5 . Our intention here is not to focus on details of the model of analysis but to emphasize the hypothesis that any model must be able to function, simultaneously, for the analysis of texts and for the analysis of genres.

The same points of analysis (in general, concerned with the conditions of production and to the text architecture) are considered in relation to the plan of the generic shape and to the plan of the organization of the singular texts. In the first case, concerning the generic shape, the task is to identify the foreseeable characteristics that constitute the identity of the genre- those characteristics we assign as parameters of genre. Characteristics are not absolutely set or mandatory, but are only predictabilities. In the second case, the one of the singular texts, 
the task is to identify the way the text (each text) assumes the predictabilities that are determined by the genre. In other words, the parameters of genre are fixed as empirical texts through what we have assigned as mechanisms of textual realization. These mechanisms concern the management of the semiolinguistics resources of a text. The correspondence between parameters and mechanisms is not fully reciprocal. In fact, the same parameter will be able to be brought up to date through different mechanisms, and it is in the specificity of the mechanisms that the singularity of each text is rooted. The textual output does not reduce itself to the mechanical application of an assembly of strict parameters. Alternatively, the existence of generic parameters, while informing the text realization, does not reveal the active role of the subjects that are able to "play strategically with the conditionings of the genre," as emphasized by Charaudeau (1992, p. 15):

The speaker always has the possibility to play with the genre constraints; he/she can comply with them, subvert or transgress them partly, according to what he/she considers to be the issue of his/ her act of communication. At the same time, any text is the result of a confrontation between the genre constraints and the strategies carried out by the speaker.

As we are trying to show, these two notions (parameters of genre and mechanisms of textual realization) maintain the possibility to notice two kinds of different objects, despite their closeness: the genres that function like standards of (relative) stability and normatization; on the other hand, the empirical texts that, taking advantage of the possibilities of generic variation, constitute always singular cases in an ultimate analysis.

In what concerns the procedure of analysis, it should be underlined that the movement starts from the real texts - the only ones directly available for analysis, in our perspective (since, as we said, the genres do not have their own ontological reality); if the survey of the mechanisms of textual realization is going to identify the parameters of genre, these must be newly confronted with the plan of the texts, in a way to assure an analysis of control.

Figure 2 presents a global vision of the considered instruments and procedures of analysis.

As we already said, the interest of the model of the displayed analysis goes, in a great measure through the possibility to articulate the description of the texts and the description of the genres, without pretending any fixation of the malleability and the mutability that are a characteristic of the category of genre ${ }^{6}$. However, we still need another notion-genre marker - to notice the way the 
subjects recognize the identity of the genres they handle.

The notion of genre marker notices the functioning of the mechanisms of textual realization in the procedure of reception/interpretation of the texts (including the situations of criticism and/or text analysis). The mechanisms function like (or work like) genre markers as they are going to identify the lines that are associated specifically to a genre. Therefore, the marker is a semiotic mechanism (of any sort) that functions like any clue or indication of the updating of a generic parameter with distinctive value.

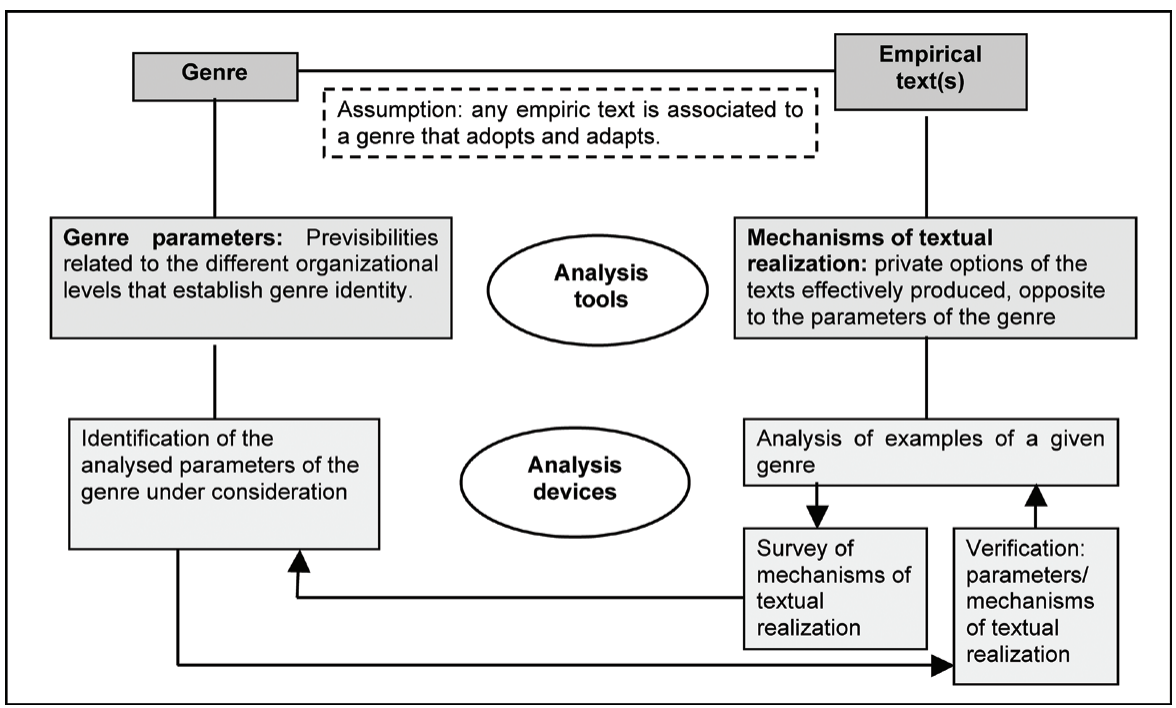

FIGURE 2: GETOC-INSTRUMENTS AND ANALYSIS DEVICES

It is possible to identify two big classes of genre markers: the self-referential and the inferential. The self-referential markers express in an explicit form the generic category of the text. Examples of this class of markers are the generic labels put in the peritext of examples of certain genres ("advertisement," "novel," "review," "interview," etc.), also the nominal syntagmas that, integrated in the body of the text, set out the genre in which the text participates ("I send this email for ...", "the objective of this paper is ...", "in the section X of this written essay...", "in this class I am going to analyze ...., etc.). Already the inferential markers indicate implicitly genre parameters and for that reason, they need more interpretative work, where the interpreter's knowledge about the genre is activated from his experience with texts of the genre in question. In principle, any class of textual realization mechanism can turn out into a genre marker (the lexicon, the syntax, the enunciative organization, the mechanisms of material presentation as the typography and the chromatic variation, etc.). One of the 
most evident examples of this class of markers is the occurrence of ritual expressions as "once upon a time ..." (short story), "I would like to request ..." (formal letter) or "mostly sunnylfew showers" (weather forecast).

Occasionally, the markers are able to function in an isolated or individual form (that is, it is possible that from the identification of only one mechanism we will be able to recognize the genre), but this verifies itself especially in the occurrence of self-referential markers. Contrarily, the inferential markers are indications that the receiver apprehends, in the majority of the cases, an interconnected form. This is so because the markers—as the parameters they indicateare specific to a genre, but not exclusive.

For the study of the markers, we propose (following Miranda, 2007) to distinguish the following semiolinguistic dimensions of the text organization: thematic (or semantic/lexical), enunciative, compositional, dispositional/material presentation, strategic/intentional and interactive ${ }^{7}$. In each dimension, we will be able to identify different species of mechanisms with the function of markers. These aspects will be resumed further on-through the examples of fictionalized genres that will be analyzed in section 5 . Before that, however, it will be necessary to set out the notion of fictionalization in the section to follow.

\section{THE FICTIONALIZATION OF GENRES AS A METHODOLOGI-}

\section{CAL STRATEGY}

By fictionalization we mean the transformation of a nonfiction genre into a fictional, playful or aesthetic one. The notion of fictionalization that we are going to use corresponds to a conceptual re-elaboration that mobilizes several contributions of literary and linguistics order. In the first place, we draw on the notion of hypertext, defined by Genette (1982) and resumed by Adam (2005, p. 15) in the following:

... retaking of a text $\mathrm{A}$ (hypotext) by a latter text $\mathrm{B}$ (hypertext) in the form of pastiche (imitation), parody (transformation), but also in the form of a simple continuation, as in translation; i.e., transposition or subversion of a text by another for humorous, satirical or serious purposes.

We also consider fundamental for the conception of fictionalization the notion of intertextualization proposed by Miranda $(2004,2007)$. This process can be defined as corresponding to the cases where a relation of co-presence is established among elements (or features) associated to parameters of textualization that are prominent of differentiated (two or more) genres in the space of only one text. In other words, a given text, inscribed in a specific genre, intertextually 
appeals to features associated with other distinct genres ${ }^{8}$.

From a relational point of view, the genre of the text in question is a "summoned" genre that functions as a hypergenre, whereas the "called" genres constitute what we will be able to name hypogenres?. Therefore, it is a dominant relation where the hypogenres are integrated in a certain way, to serve the interests of the hypergenres.

The intertextualization can assume varied forms. The hypogenres can arise actualised or fictionalized and they can fill the totality of the text (in the case of a global pastiche of a genre) or they can be integrated as portions of a text. Either actualised or fictionalized, the hypogenres can participate in several discourse strategies (Miranda, 2004).

When studying the intertextualization, one of the central problems is the recognition of the generic crossing in a text. This is how the genres in interaction can be identified semiotically (we are not concerned here with the cognitive aspects of this recognition). A first answer is that it is not a matter of a true "crossing of genres" (that is the text itself is inscribed in more than a genre), but of an effect of crossing of genres. In other words, what is "crossed" are parameters associated with different genres. These parameters can be observed (or "recuperated") through the mechanisms that materialize them. In this way, the identification of the genres in interaction is possible through the occurrence of genre markers.

In principle, a text built by the intertextualization process will have markers of the hypergenre and markers of the hypogenre. However, and given that the markers are semiotic elements, it is possible that only the markers of the hypogenre occur and that the hypergenre is only identified through situational aspects (producer, material form, etc.) and not by semiotic aspects. This is particularly visible in cases of pastiche covering the totality of the text.

To follow, we are going to observe two texts where there is intertextualization, and the hypogenres are fictionalized (or simulated). Through these cases, we will be able to notice the paper of the markers for the identification of the game of fictionalization.

We use this last term-fictionalization-in a sense not far from the one we can see from Bernié (2001), when he claims that:

... semantic variations observable among texts by the same researcher, and on the same type of scientific problem, are linked to genre variations which cannot be explained either by a simple adjustment of presentation techniques or even by the famous reflective virtues of the activity, but by a different "fictionalization" of contextual parameters of the writing activity, i.e., by the perform- 
ing and staging of a different socio-discursive context. (p. 331)

As can be seen, the author speaks of fictionalization when referring to cases where there is a staging of the contextual parameters-considering them integrated in the broader scope of genre variations. Following the same direction, we establish the distinction between genre actualization and genre fictionalization - which notions are more fully developed and exemplified in Leal and Gonçalves (2007). Within the scope of this article, we will insist on the specificity of fictionalization as simulation, or pastiche, of genre. In other words: genre is used for purposes differing from those which are in principle associated with it-humorous or playful purposes in general, advertising, aesthetic. This means that at least some genre parameters will necessarily have to be maintained, in order to ensure that the genre is recognized-a sine qua non condition to achieve the desired (humorous or other) effect.

According to what we have just finished saying we assume that to deal with texts with fictionalization of genres obliges the same genres to be taken simultaneously into account in the actualized version (and not in a fictionalization). The process offers different conditions of observation: if natural text circulation conditions remain unchanged, this makes differentiated materials available for analysis whereby these would not result from a recourse to manipulations which, however controlled, could never avoid undoing the situationality inherent to each genre.

Of this viewpoint, the fictionalization of genres can constitute a very useful strategy in the work of description of the genres and the texts—as we expect that the following section can show, through the analysis of two examples.

\section{EXEMPLIFICATION: THE ROLE OF THE MARKERS IN THE FICTIONALIZATION OF GENRES}

Appendix 1 presents an advertising announcement of a service of connection to the internet. There is, indeed, an assembly of elements (that is, "markers") that indicate the actualization of this genre. For example in the composition plan, we see the occurrence of some characteristic sections of the advertising announcements: a slogan, a mark with the respective logo and an instructive segment with facts for the obtaining of the product. Therefore, these sections have the function of inferential markers of the (hyper) genre.

If this text actualizes the genre advertisement, there is also the "summons" of another genre: the instruction manual ${ }^{10}$. This hypogenre is called to serve the argumentative interests of the announcement and it occupies a restricted space in the entire text. Indeed, barely a section of the announcement (the body of the text) corresponds to the "instruction manual." The question is how (through which clues) we recognize the presence of the instructive genre. To answer this 
question, it is necessary to identify the generic markers.

It is probable that the assembly of markers identified in the first place in the process of reading, concerns the compositional, the dispositional and the interactive dimensions. Nevertheless, there are also markers of the thematic, the enunciative and the strategic dimensions that orient our interpretative work.

From among the compositional markers, we notice the text plan (Adam, 2002a) is composed of three big sections: the title, a series of figurative drawings and a series of propositions that barely function as legends. The verbal component of the text plan (title and "legends") conforms to an injunctive sequence (Bronckart, 1999, p. 237). This sequence characterizes itself by the construction of a chaining of actions (set out in the "legends"), that constitute necessary steps to reach a result (set out in the title). In a local level, there is the reiterated occurrence of imperative phrases, whose internal composition is a structure verb + complement.

The dispositional or material markers discriminate the sections of the text plan. Indeed, it is by means of the typographical variation and the pagination that, for example, it is possible to distinguish a title from a "legend." On the other hand, the arrangement of each element of the series (drawings or propositions), establishes a construction in chain that organizes the sequence of the actions. The organization column format permits that, in the mechanism of reading in Portuguese language (from the top to the bottom and from the left to the right), the actions are interpreted like successive steps, such that the first step will be the one that is introduced in the upper position and the last step will be in the lower position of the series.

The interactive marker that highlights the identification of the instructive genre is the redundant relation between the nonverbal and the verbal components. What is said is simultaneously shown in the images. It is partly thanks to this relation that the specification of definite expressions is justified (the packaging, the CD-ROM, the reader of $\mathrm{CD}$, etc.).

We also find clues for the identification of the hypogenre in the lexicon. Indeed, the lexicon is one of the most significant thematic markers. In this case, there is, on one side, an assembly of technical words-in this case informatics (internet, CD-ROM, computer, CD reader) — and, on the other hand, an assembly of lexical items that assign actions (to catch, to open, to lay down, to put).

Concerning enunciative markers, we observe the absence of timing and space signs (deictic) and of marks of the first person. Beyond that, we see the occurrence of the second person in verbs (catch, open, lie down, put) and possessive adjectives (its).

Finally, we highlight, among the strategic/intentional markers, the reiter- 
ated occurrence of the speech act of instruction (which can be noted in each of the "captions"), the elimination of deictic linguistic structures, the lexical reiteration and the absence of subjective or valorizing elements.

The raised markers constitute semiotic clues that allow us to recognize the genre evoked in this text. In principle, all these markers actualize parameters of the hypogenre and, so, we would be able to assume that there is an actualization of the genre here. However, this segment of the advertising announcement does not function like the manual that it seems to be. If, as it is set out in the title, the actions enunciated and shown are going to instruct about the process of installation of the internet at home, such actions do not correspond to true specific steps of that process. Indeed, in a software installation manual—as this intends to be-it is not necessary to indicate what the subjects should do with the packaging of the CD-ROM. In this sense, the utterances "grab the packaging," "open the packaging," etc., do not correspond to possible or foreseeable formulations in this genre, as it functions in our society.

Still in the scope of the thematic contents, the occurrence of the closing sentence phrase "it is done" is also improbable in a text of this instructive genre. Then, two possible readings exist: either it is an actualization of genre with qualitative errors, or the "errors" are deliberate and controlled. The option for some of these interpretations, and given that this "instruction manual" is part of an advertising announcement, it is necessary to consider the argumentative strategy built in the announcement.

In this text, the central argument arises in the slogan: "fazer clix custa nix" (to do clix costs nix). This game of words between the name of the product (clix) and the ad hoc created neologism (nix) would be formulated again in the following words: "to do clix" = to link the computer to the internet and "costs nix" $=$ does not cost or it is easy. Then, the main argument of the announcement is centred in the offered simplicity of installation of the product. Thus, it is not astonishing that the "manual" is shown to be a useless or unnecessary object: since the installation is easy, the "manual" barely indicates what should be done with the packaging of the $\mathrm{CD}$ and with the $\mathrm{CD}$. Beyond that, the action of putting a CD-ROM in the computer reader is an obvious mechanical procedure for any user. The separation of this action in small actions that are, indeed, of automatic achievement, is therefore a strategic game of demonstration of the simplicity of the procedure. Thus, if it was a matter of a "true" software installation manual it would be necessary to enumerate the actions that should be carried out from the introduction of the CD-ROM in the reader and not the achievable actions to that step.

In short, the observation detailed of the genre markers in this segment of the announcement allows us to affirm that, although a big number of generic 
parameters are actualized, there is fictionalization in the plan of the thematic contents. This is verified in the kind of enunciated actions and in the occurrence of the final expression "and it is done." Later, after commenting on the second case, we will come back to this example.

Text 2 reproduced in the appendix is also a case of intertextualization. This example adds some other elements to the argument. It is a sample of the genre cartoon, as it is set out in the self-referential marker in peritextual position. In this genre, as well as in other similar genres (for example, the comics); the process of intertextualization is frequent and, perhaps still more necessary. Indeed, the nature of the cartoon is "to call" other genres inside itself. To this peculiarity, we will be able to give the name of "constitutive intertextualization" ${ }^{11}$. In that case, contrary to Text 1 , the hypogenre fills the totality of the text.

A varied assembly of markers suggest the evoked genre. From the compositional, the dispositional and the interactive viewpoint, nonverbal and verbal units compose a text plan that is characterized by the following peculiarities: (1) the presence of an image in the central position and of a series of brief utterances distributed in the upper and the lower region of the text; (2) one of the utterances is noticeable graphically by the typography, by the colour and by the location in the page ("massive destruction"); (3) in the lower region there is a relatively long segment composed by an enumeration; (4) the relation between the image and the verbal segments is basically of an illustration (because the image does not complete, substitute or repeat the information given by the utterances).

Compositionally, we also observe the occurrence of an elevated number of noun clauses and the occurrence of participial small clauses. The developed verbal sentences are few in number. The identification of a sequential organization of descriptive kind corresponds also to the plan of the composition, where the anchoring operations ("massive destruction" in the function of subject-title) and the aspectualization operations (Adam, 1992) are carried out.

Thematically, we find a salient semantic field and lexicon associated with cinematography: original argument, film, director, main actor, assembly, visual effects, etc. Ritual expressions are also invoked: "nominated for X academy Oscars," "a production X" and "filmed in X." Beyond that, we should notice the reiterated occurrence of "best," preceding the nouns relative to the cinematographic field.

It is clear that these are not the only mechanisms of textual realization that function like genre markers in this text. However, these elements look sufficient for the identification of the called genre: the poster-advertising genre of a cinematographic film.

As in Text 1 , in this example the markers actualize parameters of the hypogenre, but a fictionalization of genre is built. To arrive at this conclusion it is 
necessary to observe at least two aspects. The first aspect concerns the text situational dimension, specifically the producing entity and the support of circulation: someone signs this sample (which does not happen in advertising) and it is published in the section of a magazine entitled "recreational society," and is further labeled as a cartoon. The second aspect is the thematic organization: the nouns that occur in the text do not correspond to the world of the makers of the cinematographic fiction, but to the world of the makers (contemporary to the text) of the Anglo-American political reality: Tony Blair, George W. Bush, CIA and British Secret Service, etc. Then, this text relates in fiction an advertising poster of a film that does not exist nor would be able to exist. The fictionalization of a cinematographic advertising poster here accomplishes critical humor.

These two observed examples are different kinds of fictionalization of genres, but both coincide in the particular plan that establishes the fictionalization, i.e., in the organization of the thematic contents. Despite this coincidence, the two examples show that the occurrence of fictionalized thematic contents does not concern exclusively the mobilization of fictional contents, as in the case of the film that never existed referred to in Text 2. Indeed, we notice that in Text 1 there is no "fictional" contents, but there is an infringement on the norms (or parameters) of the genre. This is a thematic infringement, since it concerns, specifically, the propositional contents of the enunciated actions. Thus, to fictionalize parameters of a genre does not necessarily introduce imaginary elements. It rather subverts a genre, creating another reality where the infringements are not infringements anymore. This is a game of creation of an action where everything (in semiotics) is admissible. In practice: in Text 1, the enunciated actions are inappropriate in relation to the norms of the genre "instruction manual," according to the operation of this genre in our daily life; however, in the fiction created in the announcement (in another reality) this is a plausible manual.

Genre markers play an important role in the interpretation of the intertextualization and, particularly, of the fictionalization of genres. These examples demonstrate that the identification of the generic markers (self-referential or inferential) is an essential procedure in the process of reading or listening to the texts. By means of the recognition of these semiotic clues, the subjects are capable of interpreting the generic inscription of a text. This process of comprehension of the generic inscription of the text is fundamental to assure the communication (according to, among others, Bakhtin, 1992 and Maingueneau, 1998). Without doing that interpretative work, the subjects-receivers do not play the game proposed by the subjects-producers. From both the theoretical and applied viewpoint, the detailed observation of the hypogenres markers distinguishes the mechanisms of textual realization that respect the norms of the genre and the 
mechanisms subverting them.

\section{FINAL CONSIDERATIONS}

This work started from the need to answer two questions: on one side, to know in what measure the genres can be described, although by definition they are only accessible through the empirical texts that actualize them; on the other, to verify up to where there is or there is not a convergence in the work about genres and about texts.

To face these questions we have presented some instruments of analysis that, to our knowledge, make the distinction (but also the articulation) viable of near but not coincidental objects of analysis: the genres, while abstract categories, and the empirical texts that constitute always a sample of a determined genre. Thus, we assume that each genre can be described through an assembly of parameters - parameters that, to the empirical level of the text, can carry out a differentiated form, constituting what we assign as mechanisms of textual realization. As we also saw, those mechanisms can function like genre markers-in the measure that they are going to identify, or to make recognizable, the genre in question, in a situation of textual reception/interpretation.

We have identified the fictionalization of genres as a particular case of intertextualization (as a process which places in a co-presence relation two or more genres within a text) as we have shown the highlighting function that falls to the genre markers, in the cases of fictionalization. Enumerating these signs makes it possible to detect the semio-lingustic dimensions in which fictional or transgressive elements appear and, at the same time, makes it possible to point out the specific tools in which fiction/transgression materializes. This enumerating also allows the understanding that the fictionalization of a genre does not imply the total subversion of the generic parameters. Indeed, to recognize the fictionalized genre some parameters should be necessarily actualized without absolute infringements. This is the reason why the cases of fictionalization are going to constitute a privileged occasion of analysis for us: without the manipulated interference of the researcher, the genre shows itself in the double role of the actualization (or lineal adoption) and of the fictionalization (or simulation).

The two examples observed show different ways of fictionalization of genres and the markers' participation in this process. In one of the cases (Text 2), a fictional subject/object is built: the film spoken on the text does not exist. In another case (Text 1), there is an infringement on the thematic parameters of the genre, because topics not predicted by the genre in question are introduced.

Also worth underlining is that the fictionalization of genres (or the fictionalization or infringement of the parameters) is not carried out only in the plan of thematic content organization. This means that there may be texts in which enunciative or compositional mechanisms indicate the fictional convening of a 
genre other than that in which the texts are inscribed. That is why the choice of the two commented examples should not cause us to conclude that the thematic markers constitute the only possible clues for the identification of the phenomenon. Indeed, hypothetically, any class of marker would be able to fill that function.

To uncover cases that show this we need to continue to observe with curiosity the infinite textual world that surrounds us. And that necessary empirical work about texts of different genres will alone be able to show conclusively the operating efficiency of the proposals presented here.

\section{APPENDIX A}

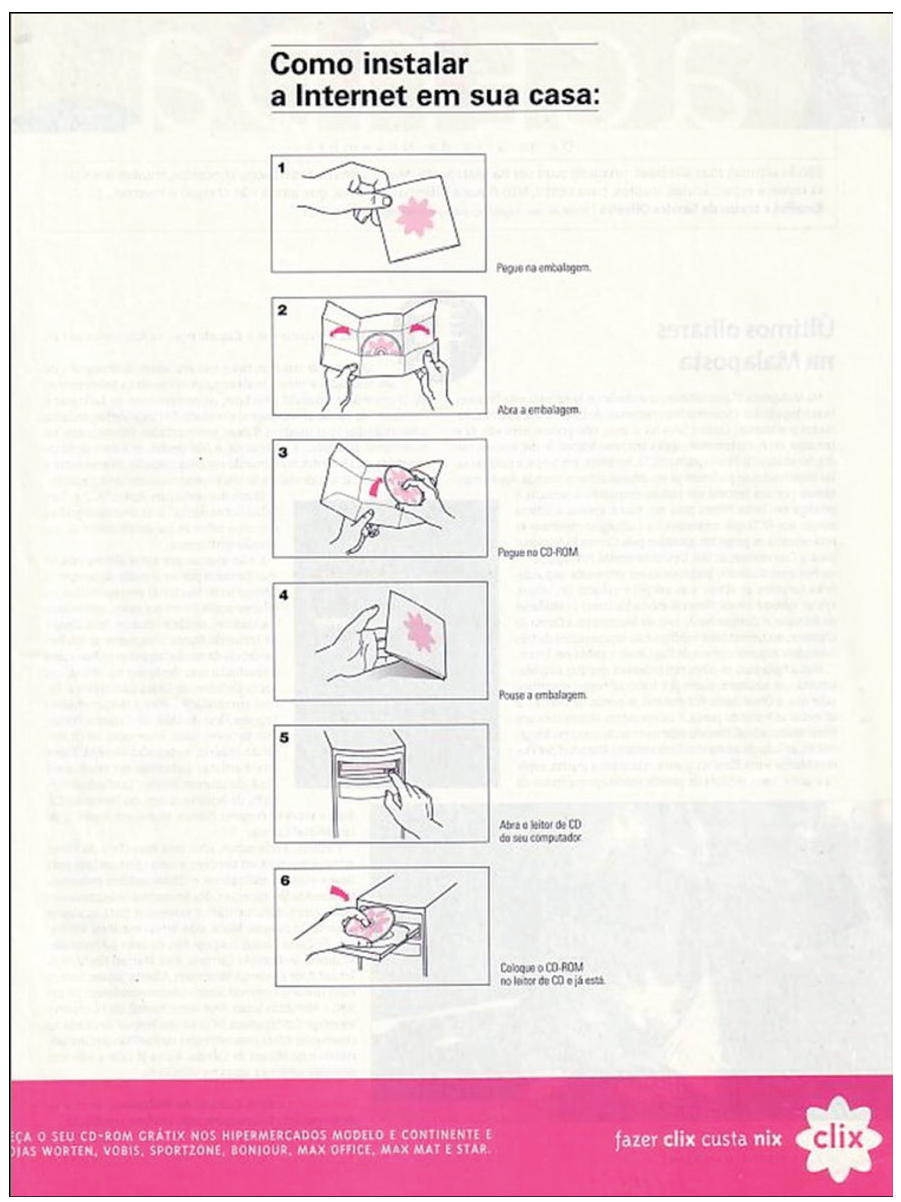

TEXT 1: PUBLISHED NOVEMBER 11, 2001 IN NOTÍCIAS MAGAZINE (PORTUGAL), P. 101 


\section{APPENDIX B}

$\begin{aligned} & \text { Sociedade } \\ & \text { recreativa }\end{aligned} \quad$ Luis Afonso

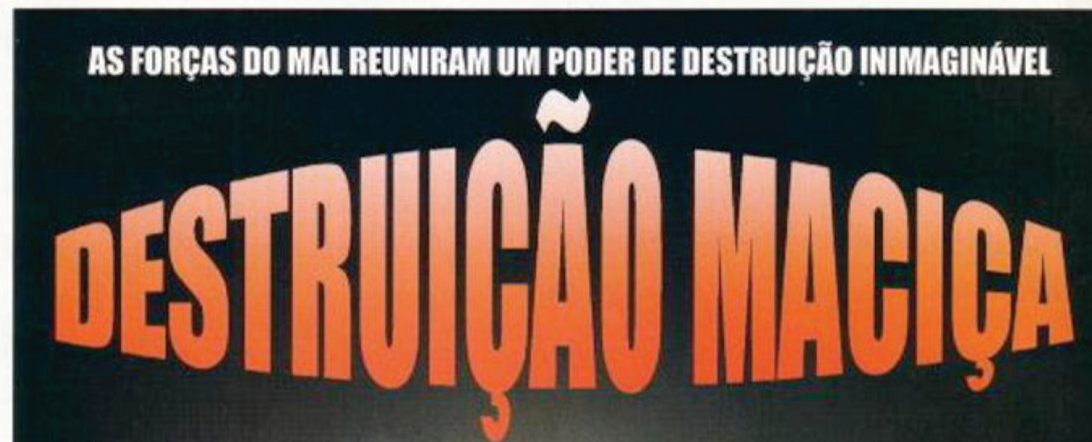

\section{SÓ A GORAGEME A DEEERMIXAĢIOO PODERT̃O SALUAR O MUNDO}

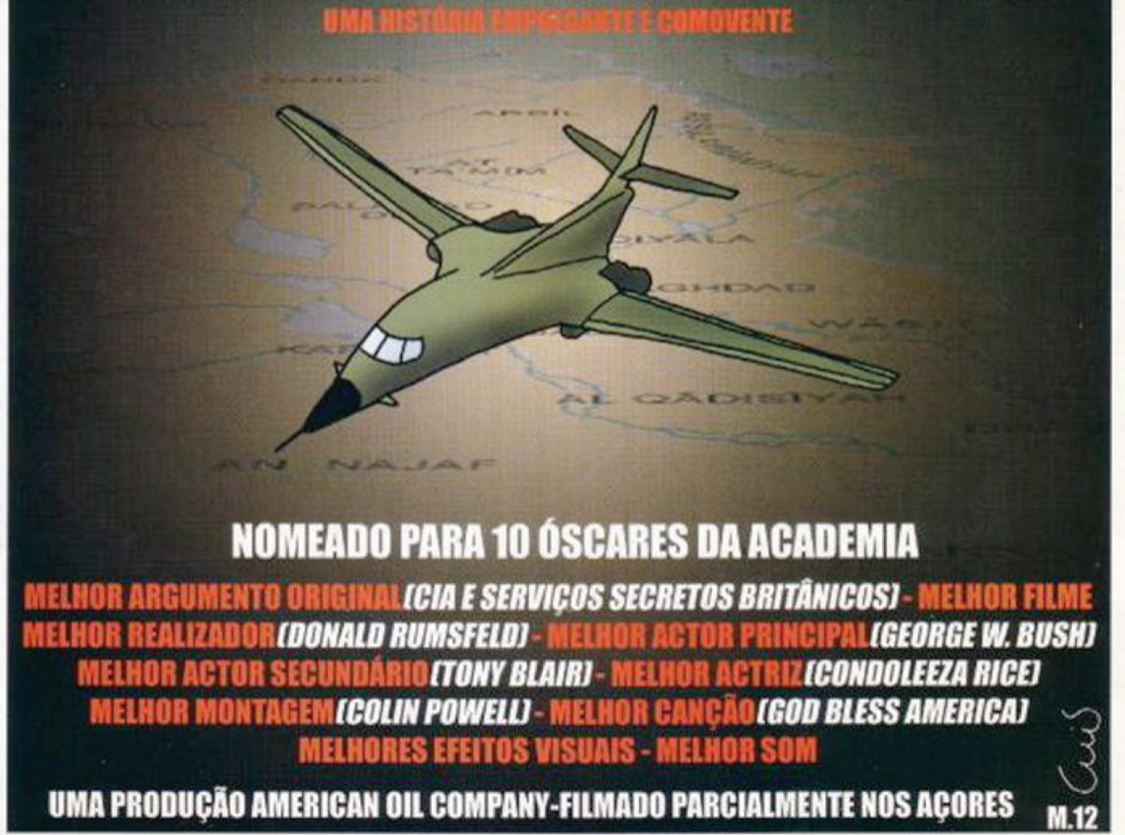

TEXT 2: PUBLISHED FEBRUARY 8, 2004, IN REVISTA PÚBLICA (PORTUGAL), P. 4 


\section{NOTES}

${ }^{1}$ As underlined by J. M. Adam, the three dimensions in Bakhtin (1984) are close to the ancient rhetorical triad-the inventio, the dispositio and the elocutio. (Adam, 1999, p. 92).

${ }^{2}$ In French: discours interactif and discours théorique (ordre de l'exposer); récit interactif and narration (ordre du raconter) (Bronckart, 1997).

3 Those levels of text organization are previously referred, in the same article, in five blocks: phrastic and trans-phrastic, compositional structure (sequences and text plans), semantics (discourse representation), enunciation (situational anchoring and responsibility), speech acts (illocutionary) and argumentative orientation (Adam, 2001, p. 41).

${ }^{4}$ These notions are a product of the inquiry in Text Theory developed in the Faculdade de Ciências Sociais e Humanas of the Universidade Nova de Lisboa. Two of them (parameters of genre and mechanisms of textual realization) were developed within the framing of the sub-project Géneros Textuais e Organização do conhecimento-GeTOC (Textual Genres and Organization of the Knowledge), integrated in the project DISTEX (Linguistics Centre of the New University of Lisbon, 2003-2006). The third (genre markers) is an elapse of the study of Florencia Miranda, within her PhD research (Miranda, 2007).

${ }^{5}$ For more details, see Coutinho, Alves, Gonçalves, Miranda, \& Pinto (2008, forthcoming); Leal \& Gonçalves (2007).

${ }^{6}$ Indeed, the distinction between parameters of genre and mechanisms of textual realization is going to grasp the (synchronic) variation and, in that same measure, contribute to the possibility of the diachronic perspective (thus identifying the process of generic change).

${ }^{7}$ This proposal based itself in a critical reading of the contributions of authors such as Adam, Bronckart and Maingueneau. For a more detailed presentation, see Miranda (2007). For an approach to the proposals of these theoreticians, it is possible to see, among others, Adam (2001), Bronckart (1999) and Maingueneau (1998).

${ }^{8}$ It is important to highlight that, the way as it is here assumed (and it was proposed in Miranda, 2004 and 2007), this process should be differentiated from the "intertextuality" phenomenon (in the strict sense), whose specificity is to put in co-presence two or more empirical texts in the same textual space. Despite the proximity of the notion that is proposed here with the notion of "intergeneric intertextuality" that Marcuschi (2003, p. 31) utilizes in the sequence of the works of Ulla Fix, the term intertextualization is not limited to the cases where exists, as Marcuschi says, "a mixture of functions and forms of genre diverse in a given genre."

9 The use of the prefixes "hyper-" and "hypo-"arises here in the sequence of 
Gérard Genette (and of his studies about the transtextuality), but putting the focus of the problem in the genres and not alone in the texts. For the Genette perspective about the hypertextuality, see Genette (1982).

${ }^{10}$ We are going to underline that others can replace the generic "labels" that we are using without any prejudice to the analysis. In principle, for the characterization of the genres it is irrelevant that the genre be nominated socially by only a name or by multiple denominations. Therefore, it does not matter, as an example, if the genre of this text is called "advertising announcement" or "publicity."

${ }^{11}$ The constitutive intertextualization opposes itself to the strategic intertextualization. This distinction is also a proposal developed in Miranda, 2007.

\section{REFERENCES}

Adam, J.-M. (1992). Les textes: Types et prototypes. Paris: Nathan.

Adam, J.-M. (1999). Linguistique textuelle: Des genres de discours aux textes. Paris: Nathan.

Adam, J.-M. (2001). En finir avec les types de textes. In M. Ballabriga (Org.), Analyse des discours. Types et genres: Communication et interprétation (pp. 25-43). Toulouse, France: EUS.

Adam, J.-M. (2002a). De la période à la séquence: Contribution à une (trans) linguistique textuelle comparative. In H. L. Andersen \& H. Nølke (Eds.), Macro-syntaxe et macro-sémantique (pp.167-188). Bern, Switzerland: Peter Lang.

Adam, J.-M. (2002b). Plan de texte. In P. Charaudeau \& D. Maingueneau (Eds.), Dictionnaire d'Analyse du Discours (pp. 433-434). Paris: Seuil

Adam, J.-M. (2005). La translinguistique des textes à l'œuvre. In P. Lane (Dir.), Des discours aux textes: modèles et analyses (pp. 11-38). Rouen, France: Publication des Universités de Rouen et du Havre.

Bakhtin, M. (1992). Estética da Criação Verbal. São Paulo: Martins Fontes.

Bakhtin, M. (1977). Le marxisme et la philosophie du langage. Paris: Minuit.

Bernié, J. P. (2001). Les genres discursifs, des outils sociaux de transformation des connaissances. In M. Ballabriga (Org.), Analyse des discours. Types et genres: Communication et interprétation (pp. 331-355). Toulouse, France: EUS.

Bronckart, J. P. (2006). Atividade de linguagem, discurso e desenvolvimento humano. Campinas, São Paulo: Mercado de Letras

Charaudeau, P. (1992). Grammaire du sens et de l'expression. Paris: Hachette.

Coutinho, M. A., Alves, M., Gonçalves, M., Miranda, F., \& Pinto, R. (in press). Parâmetros de géneros e mecanismos de realização textual—aspectos teóricos. Diacrítica. Braga, Portugal: Universidade do Minho

Genette, G. (1982). Palimpsestes. Paris: Seuil. 
Leal, A., \& Gonçalves, M. (2007). Gêneros ficcionalizados e identidade de género. In A. Bonini, D. Figueiredo, \& F. Rauen (Eds.), Proceedings of the 4th International Symposium on Genre Studies [CD] (pp. 696-707). Tubarão, Santa Catarina, Brazil: University of Southern Santa Catarina.

Maingueneau, D. (1996). Les termes clés de l'analyse du discours. Paris: Seuil.

Maingueneau, D. (1998). Analyser les textes de communication. Paris: Dunod.

Maingueneau, D. (2002). Un genre de discours. In C. Dardy, D. Ducard, \& D. Maingueneau (Eds.), Un genre universitaire: Le rapport de soutenance de thèse (pp. 47-86). Lille, France: Presses Universitaires du Septentrion.

Marcuschi, L. A. (2003). Gêneros textuais: Definição e funcionalidade. In A. P. Dionísio, A. R. Machado, \& M. A. Bezerra (Eds.), Gêneros textuais e ensino (pp. 19-36). Rio de Janeiro: Editora Lucerna.

Miranda, F. (2004). Aspectos do cruzamento de géneros como estratégia discursiva. In M. A. Marques, M. E. Pereira, R. Ramos, \& I. Ermida (Eds.), Práticas de investigação em análise linguistica do discurso. Actas do II encontro internacional de análise linguística do discurso (pp. 195-211). Braga, Portugal: Universidade do Minho

Miranda, F. (2007). Textos e géneros em diálogo-uma abordagem linguistica da intertextualização. Unpublished doctoral thesis, Universidade Nova de Lisboa, Lisboa, Portugal.

Rastier, F. (2001). Arts et sciences du texte. Paris: PUF. 